\title{
Mechanisms associated with resistance to tamoxifen in estrogen receptor-positive breast cancer (Review)
}

\author{
RUBÍ VIEDMA-RODRÍGUEZ ${ }^{1,2}$, LUIS BAIZA-GUTMAN ${ }^{2}$, FABIO SALAMANCA-GÓMEZ ${ }^{1}$, \\ MARIANA DIAZ-ZARAGOZA ${ }^{3}$, GUADALUPE MARTÍNEZ-HERNÁNDEZ ${ }^{2}$, RUTH RUIZ ESPARZA-GARRIDO ${ }^{1}$, \\ MIGUEL ANGEL VELÁZQUEZ-FLORES ${ }^{1}$ and DIEGO ARENAS-ARANDA ${ }^{1}$ \\ ${ }^{1}$ Molecular Genetics Laboratory, Medical Research Unit in Human Genetics, Pediatric Hospital, National Medical Center \\ Century XXI (CMN-SXXI), Mexican Social Security Institute (IMSS), Mexico City; ${ }^{2}$ Unit of Morphology and Function, \\ Faculty of Higher Studies (FES) Iztacala, National Autonomous University of Mexico (UNAM), Los Reyes Iztacala, \\ State of Mexico; ${ }^{3}$ Biomedical Research Institute (IIBM), UNAM, Mexico City, Mexico
}

Received February 14, 2014; Accepted April 3, 2014

DOI: $10.3892 /$ or.2014.3190

\begin{abstract}
Anti-estrogens such as tamoxifen are widely used in the clinic to treat estrogen receptor-positive breast tumors. Patients with estrogen receptor-positive breast cancer initially respond to treatment with anti-hormonal agents such as tamoxifen, but remissions are often followed by the acquisition of resistance and, ultimately, disease relapse. The development of a rationale for the effective treatment of tamoxifen-resistant breast cancer requires an understanding of the complex signal transduction mechanisms. In the present study, we explored some mechanisms associated with resistance to tamoxifen, such as pharmacologic mechanisms, loss or modification in estrogen receptor expression, alterations in co-regulatory proteins and the regulation of the different signaling pathways that participate in different cellular processes such as survival, proliferation, stress, cell cycle, inhibition of apoptosis regulated by the Bcl-2 family, autophagy, altered expression of microRNA, and signaling pathways that regulate the epithelial-mesenchymal transition in the tumor microenvironment. Delineation of the molecular mechanisms underlying the development of resistance may aid in the development of treatment strategies to enhance response and compromise resistance.
\end{abstract}

\section{Contents}

1. Introduction

2. Estrogen action and function

3. Mechanism of tamoxifen resistance

Correspondence to: Dr Diego Arenas-Aranda, Molecular Genetics Laboratory, Medical Research Unit in Human Genetics, Pediatric Hospital, National Medical Center Century XXI (CMN-SXXI), Mexican Social Security Institute (IMSS), 330 Cuauhtemoc Avenue, Mexico City 06729, Mexico

E-mail: arenasdi@gmail.com

Key words: breast cancer, tamoxifen, pathway signaling
4. Signaling pathways that regulate epithelial-mesenchymal transition in tumor microenvironment

5. Conclusion

\section{Introduction}

Estrogens and their receptors (ERs) influence many physiological processes in mammals and are also implicated in the development or progression of numerous diseases, including various types of cancer (breast, ovarian, colorectal, prostate and endometrial), osteoporosis, neurodegenerative diseases, cardiovascular disease, insulin resistance, lupus erythematosus, endometriosis and obesity (1-3). Breast cancer is the most frequently detected female neoplasm worldwide. The ER is expressed by $60-70 \%$ of breast tumors $(4,5)$ and the mechanism has been studied; binding of estrogens to ER stimulates proliferation of mammary cells, increasing the target cell number within the tissue, and the increase in cell division and DNA synthesis elevates the risk for replication errors, which may result in the acquisition of detrimental mutations that disrupt normal cellular processes such as apoptosis, cellular proliferation or DNA repair. A second mechanism of estrogen metabolism leads to the production of genotoxic by-products that could directly damage DNA, again resulting in point mutations. There is evidence that estrogen may act through both mechanisms to initiate and/or promote mammary cancer (2). In the treatment of breast cancer, tamoxifen is the most commonly used anti-estrogen, but resistance remains an obstacle in the treatment of hormone-dependent breast cancer. While up to one third of patients are resistant to tamoxifen at the beginning of treatment, the majority of patients who initially respond to tamoxifen will later also become resistant. Some mechanisms may include changes in the expression of $E R \alpha$ or $E R \beta$, an alteration in co-regulatory proteins and an alteration in transduction pathways, altered expression of specific microRNA, and genetic polymorphisms involved in tamoxifen metabolic activity. Due to the clinical consequences of endocrine resistance, new treatment strategies are arising to render the cells sensitive to tamoxifen. In the present study, 
we reviewed the current knowledge on the mechanisms of endocrine resistance in breast cancer cells.

\section{Estrogen action and function}

Estrogens perform their function by interacting with ER. Two ER genes have been identified in mammals: ER $\alpha$ and ER $\beta$, which show similar DNA- and ligand-binding properties, but distinct tissue distributions and functions (6-8). The ER is a member of the nuclear receptor family of ligand-activated transcription factors. After entering the cell, estrogen binds the ER, which dissociates from heat shock proteins (HSPs) and undergoes conformational changes, phosphorylation and dimerization before binding to the estrogen response elements (ERE) upstream of estrogen-dependent genes. This is referred to as the classical mode of action. The majority of these genes in this model are involved in cell proliferation and survival or in maintaining tissular architecture $(9,10)$. Ligand-bound ER can also modulate gene expression through interaction of the receptor with Fos and Jun at activator protein-1 (AP-1) binding sites (11) or with specificity protein 1 (SP-1) sites in DNA, thereby functioning as a co-regulator (12). Co-regulators serve as a fine tuning mechanism by increasing or reducing the receptor transcriptional activity (13). Several co-regulators have been implicated in cancer, most notably AIB1 (SRC-3), a gene that is amplified in a small percentage but overexpressed in two thirds of all breast cancers. Overexpression of this gene has been implicated in tamoxifen resistance $(14,15)$.

In the ligand-independent mechanism, ER is phosphorylated by membrane receptor tyrosine kinases including the epidermal growth factor receptor (EGFR) (16), ErbB receptor 2 (ERBB2/HER2), and the insulin-like growth factor receptor (IGF1-R) (17) or signaling molecules leading to dimerization, DNA binding, and the activation of transcription (18). Crosstalk between the growth factor receptors (GFR) and ER pathways has been established through several other mechanisms. Estrogen can increase the expression of ligands such as transforming growth factor- $\alpha$ (TGF $\alpha)$ and IGF1 $(12,19,20)$ which can then activate the GFR pathway $(17,20)$. On the other hand, estrogen signaling downregulates the expression of EGFR and ERBB2/HER2 while it induces the expression of IGF1-R (21). Activation of the phosphoinositide 3 kinase (PI3K)-kinase AKT (AKT) and the p42/44 mitogen-activated protein kinase (MAPK) pathways by these receptors, in turn, downregulates the expression of ER and progesterone receptors (PR) $(22,23)$. Thus, while receptor tyrosine kinases can activate the transcriptional function of ER, they can also reduce estrogen dependence by downregulating the expression of ER, perhaps contributing to the relative resistance to endocrine therapies in tumors amplified for ERBB2/HER2 (24). Studies also suggest that ER may work by non-transcriptional mechanisms. Low levels of ER have been found outside of the nucleus, in the membrane, cytoplasm or even in the mitochondria, although the exact location for this receptor remains controversial (25). Some of the non-genomic action of estrogen appears to be too rapid for a transcriptional effect to active GFR signaling, including the PI3K/AKT and Ras/p42, 44 MAPK pathways. Thus, ER, through this non-genomic activity, can alter the expression of genes normally regulated by growth factors $(25,26)$. Finally, the stress kinase pathway via p38 and
JNK can also modulate ER function by phosphorylation of ER and its co-regulators (27). The microenvironment and its associated integrin signaling may exert similar activity (28). Thus, ER activity and signaling is modulated by a variety of pathways, which could also contribute to resistance to ER-targeted therapies, especially when the pathways display aberrant activity in a cancer cell.

\section{Mechanism of tamoxifen resistance}

Several mechanisms of resistance to tamoxifen have been studied and include the following: pharmacologic mechanisms; loss or modification in ER expression; alterations in co-regulatory proteins and regulation of different signaling pathways that participate in the cellular process, such as survival, proliferation, stress response, cell cycle, inhibition of apoptosis regulated by the Bcl-2 family, autophagy, altered expression of microRNAs and signaling pathways that regulate epithelial-mesenchymal transition (EMT) in the tumor microenvironment. Some proposed mechanisms responsible for tamoxifen resistance are described below (Fig. 1).

Pharmacologic mechanisms. Cytochrome P450 2D6 (CYP2D6) is crucial in the metabolism of tamoxifen to its active metabolite, endoxifen (29). Retrospective clinical data suggest that specific single nucleotide polymorphisms (SNPs) of CYP2D6 can lead to null or reduced enzyme activity resulting in poorer outcomes for patients with these when they are treated with tamoxifen for hormone receptor (HR)-positive breast cancer (30). Polymorphic CYP2D6 is the key enzyme in this biotransformation, and recent mechanistic, pharmacologic and clinical evidence suggests that genetic variants and drug interaction with CYP2D6 inhibitors exert an influence on the plasma concentrations of active tamoxifen metabolites and the outcomes of tamoxifen-treated patients. In particular, non-functional (poor metabolizer) and severely impaired (intermediate metabolizer) CYP2D6 alleles are associated with higher recurrence rates (31).

Loss or modification in ER expression. Expression of ER $\alpha$ has long been considered a determinant of a clinical response to endocrine or anti-estrogen therapy. The ER $\alpha$ status of breast tumors provides prognostic information and is the primary target for endocrine therapy. Effective strategies to treat ER-positive breast cancer include endocrine agents that compete with estrogen for binding to its receptor, such as selective estrogen-receptor modulators (SERM) and antiestrogens or reducing the levels of circulating estrogens by the administration of agents such as third-generation aromatase inhibitors (32), which have been shown to be more effective than tamoxifen in postmenopausal women in neoadjuvant and adjuvant settings (33). Patients with tumors lacking ER $\alpha$ generally do not benefit from tamoxifen therapy, although a fraction of ER $\alpha$-negative tumors appear to be sensitive to tamoxifen (34). Several studies have measured ER $\beta$ in breast cancer tumors and have sought to clarify the relationship between ER $\beta$ and its role in response to endocrine treatment; however, some of the results have been conflicting and the majority have focused on ER $\beta$ as a resistance marker in ER $\alpha$-positive tumors $(35,36)$. ER $\beta$ has been shown to bind tamoxifen (37), and it has been 


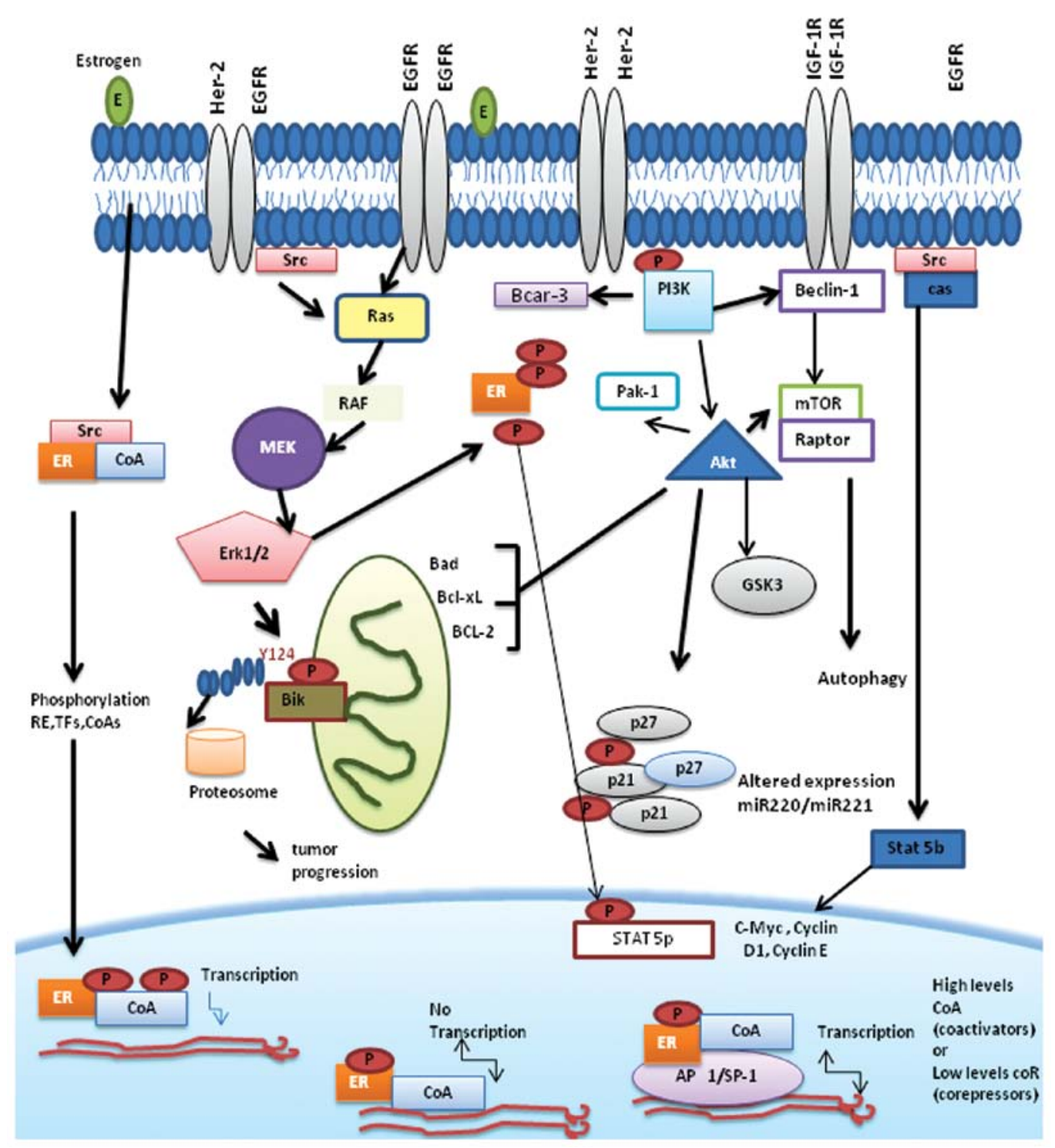

Figure 1. Molecular mechanism of tamoxifen resistance. Model of molecules implicated in anti-estrogen resistance and discussed in this review.

suggested that low levels of ER $\beta$ are associated with tamoxifen resistance (35). Conversely, some studies have shown that the expression of ER $\beta$ had a beneficial effect on disease-free and overall survival in a group of 186 tamoxifen-treated tumors; however, the authors found no such association in their set of 119 untreated patients, suggesting a role for $E R \beta$ as a predictive marker for tamoxifen sensitivity, but not as a prognostic marker (36).

Several mechanisms have been proposed to explain the absence of ER expression. These mechanisms comprise epigenetic changes, such as aberrant $\mathrm{CpG}$ island methylation of the ER promoter and histone deacetylation, resulting in a compact nucleosome structure that limits transcription (38-40). Co-treatment with inhibitors of DNA methyltransferase-1 (DNMT-1), such as 5-Aza-2-deoxycytidine (AZA), or inhibitors of histone deacetylase (HDAC), like trichostatin A (TSA) and suberoylanilide hydroxamic acid (SAHA), induce ER gene expression in ER(-) breast cancer cells and restore sensitivity to anti-estrogen $(38,41,42)$. In ER(-) MDA-MB-231 cells, which overexpress EGFR, SAHA may not only reactivate silenced ER, but it also simultaneously depletes EGFR expression and abolishes EGF-initiated signaling pathways including phosphorylated p21-activated kinase-1 (PAK1), p38MAPK and AKT (43). In vitro and in vivo studies showed that treatment with the histone deacetylase inhibitor entinostat (ENT) increased the expression of $E R \alpha$ and aromatase. Notably, $E R \alpha$ and aromatase upregulation resulted in sensitization of breast cancer cells to estrogen and letrozole (44).

Another mechanism that has been studied is mutations in ER genes that may lead to a functionally negative ER phenotype without the loss of ER expression as determined by proteinbased immunohistochemical assays. Using site-directed mutagenesis in the AF-2 region of mouse ER, it is possible to reduce estrogen-dependent transcriptional activation without significantly affecting hormone and DNA binding (45). A mutation substituting aspartate for tyrosine at position 351 has been identified in a tamoxifen-stimulated cell line (46). More recently, substitution of aspartate with glycine at amino acid 351 in the ER has been shown in an experimental system to silence the agonist activity of 4-hydroxytamoxifen (47). 
However, it has been reported that only $17-28 \%$ of patients with acquired resistance to tamoxifen lose the expression of $\mathrm{ER} \alpha(47)$.

Several kinase pathways have been associated with tamoxifen resistance, including activation of the protein kinase A (PKA) (17), MAPK (18) and PAK-1 signaling pathways (19). These kinases induce phosphorylation of ER $\alpha$ or of its co-regulators. Some phospho-modification sites have been studied in ER $\alpha$ that could contribute to an altered response to tamoxifen and in which kinase pathways and upstream activators are involved.

Serine residues S102, S104 and S106 at the N-terminal AF-1 region of ER $\alpha$ are phosphorylated by glycogen synthase kinase-3 (GSK-3) and by extracellular signal-regulated kinases 1 and $2(E R K 1 / 2)$ and MEK1/2 pathways; these modifications lead to ligand-independent transcription of ER $\alpha$ and to an agonistic activity of tamoxifen $(48,49)$. S102, a phosphorylation site discovered by mass spectrometry, requires concurrent phosphorylation of S104 (50). ER $\alpha$ phosphorylation by GSK-3, which also targets S118, stabilizes ER $\alpha$ without ligand and modulates ER $\alpha$ transcriptional activity upon ligand binding. S104 and S106 can also be phosphorylated by the CDK2/cyclin A complex (51). Cyclin A has been reported as a predictive marker for tamoxifen resistance in patients with breast cancer (52).

Serine 118 is one of the most reported phosphorylation sites of ER $\alpha$. It is targeted by a number of kinase pathways: MAPK, GSK-3, IKK $\alpha$, CDK7 and the mammalian target of rapamycin (mTOR)-p70 S6 ribosomal kinase (p70S6K) and S118 phosphorylation by MAPK increases the binding of co-activator SRC3 and renders ER $\alpha$ hypersensitive to estradiol (53). Phosphorylated S118 decreases ER $\alpha$ affinity for tamoxifen and reduces binding to DNA, when ER $\alpha$ is tamoxifen bound (54). Upstream, the RAS/MAPK pathway can be activated by IGF stimulation inducing phosphorylation of $\mathrm{ER} \alpha \mathrm{S} 118$ and resulting in ER $\alpha$ activation and enhanced response to estradiol (55).

Serine 282 resides in the hinge region and, similar to $\mathrm{S} 167$, can be phosphorylated by CK2. Estradiol increases phosphorylation of S282, stabilizes ER, and induces transcriptional activity (50).

Serine 305 resides at the $\mathrm{C}$-terminus of the hinge region, which provides a center of rotation to the total $E R \alpha$. The region around Ser305 is a multifunctional domain that binds to many co-regulatory proteins and is involved in the regulation of the activity and stability of $E R \alpha(56,57)$.

Phosphorylation of Ser305 occurs by means of protein kinase A (PKA) and is associated with resistance to tamoxifen in patients.

Alterations in co-regulatory proteins. The transcriptional regulatory activity of ER is mainly mediated by the formation of complexes with co-activator or co-repressor proteins. In general, co-activators bind the ER when it is bound by estrogen, enhancing target gene transcription. When an antagonist such as tamoxifen is bound to ER, co-repressors are typically recruited, which results in repression of target gene transcription. Under specific conditions, such as high ERBB2/ HER2 activity, a tamoxifen-ER complex may also recruit co-activator proteins, causing agonistic effects.
Altered expression of co-regulators may therefore play a role in tamoxifen resistance $(58,59)$. It has been demonstrated in vitro that co-activator proteins AIB1, PGC- $1 \beta$ and SRC1 enhance the agonistic activity of tamoxifen $(60,61)$. In patients receiving adjuvant tamoxifen therapy, high levels of AIB1 alone or in combination with high levels of ERBB2/HER2 are associated with shorter disease-free survival in patients (62).

These findings support a role for the overexpression of co-activators in tamoxifen resistance. However, high levels of SRC1 were associated with favorable response to tamoxifen in patients (61), which is not in line with this hypothesis. The presence of other factors, such as ERBB2/HER2, may play a role in this outcome (59). In addition, two studies showed that low levels of the co-repressor protein NCOR1 predict poor response to tamoxifen (63). These results support the possibility that reductions in co-repressor activity may also contribute to tamoxifen resistance.

Growth factor receptor signaling pathways. Estrogen receptor may initiate rapid cellular signaling via direct interaction with components of growth factor signaling pathways. Several studies have found that overexpression of EGFR or ERBB2/HER2 in ER-positive, anti-estrogen-sensitive breast cancer confers resistance to this drug $(3,64)$. EGFR and HER2 are associated with reduced response to tamoxifen that, in experimental systems, can actually stimulate their growth $(15,16)$.

Gefitinib, which inhibits ERBB2/HER2, improved the antitumor effect of tamoxifen and delayed the acquisition of resistance, but had no effect on estrogen-stimulated growth. Phosphorylated levels of p42/44 and p38 MAPK (both downstream of EGFR/HER2) were increased in tamoxifenresistant tumors and were suppressed by gefitinib. There was no apparent increase in phosphorylated AKT, (also downstream of EGFR/HER in resistant tumors, but it was nonetheless suppressed by gefitinib. Phosphorylated IGF-1R, which can interact with both EGFR and membrane ER, was elevated in the tamoxifen-resistant tumors compared with the sensitive group. However, ER-regulated gene products, including total IGF-IR itself and the PR, remained suppressed even at the time of acquiring resistance. Tamoxifen's antagonism of classic ER genomic function was retained in these resistant tumors and even in tumors that overexpress ERBB2/HER2 (MCF-7 HER2/18). In conclusion, EGFR/HER2 may mediate tamoxifen resistance in ER-positive breast cancer despite continued suppression of ER genomic function by tamoxifen. IGF-IR expression remains dependent on ER but is activated in tamoxifen-resistant tumors (65).

$I G F-1 R$. The IGF-1R signaling pathway has important roles in regulating energy metabolism, cellular proliferation and apoptosis. IGF-1R is a receptor tyrosine kinase that exerts its biologic effects through binding of the ligands IGF-I and IGF-II. Following ligand binding and receptor activation, adaptor molecules are recruited, leading to activation of downstream pathways, including the RAS/MAPK and PI3K pathways $(66,67)$. The expression of ER is controlled by IGF in breast cancer cells (68). Conversely, genomic and non-genomic actions of ER can activate the mitogen-inducing signals of the IGF pathway (69). Estrogen signaling can also enhance 
IGF-1R signaling through transcriptional upregulation of IGF1R, IRS-1 and IGF-II (70-72). Reciprocally, IGF1R has been shown to phosphorylate and activate ER in serine-167 through an S6-kinase mechanism (73). One mechanism by which IGF-1-treated breast cancer cells may escape from tamoxifen-induced apoptosis is via IGF-mediated activation of AKT and subsequent phosphorylation of ER, leading to the ligand-independent activation of ER (74). Previous in vitro studies have aimed to elucidate the role of IGF-1R in breast cancer resistance. A gene that confers resistance to tamoxifen is for IGF binding protein 5 (IGFBP5) (75). IGFBP5 is a secreted protein that inhibits growth factor binding to IGF-1R (76). In addition, IGFBP5 has recently been shown to play a critical role in breast cancer progression and metastasis (77). Studies have demonstrated that knockdown of IGFBP5 resulted in resistance to tamoxifen treatment in $\mathrm{MCF}-7$ cells and in mice tumor xenografts. IGFBP5 knockdown-induced resistance to tamoxifen occurred potentially via altered IGF signaling and loss of ER expression $(55,68,78)$. It has also been shown that inhibition of IGF-1R (by an anti-IGF-1R antibody) (79) or by an IGF-1R tyrosine kinase inhibitor (80) reduces the growth of tamoxifen-resistant MCF-7 breast cancer cells. Furthermore, it has been demonstrated in an in vivo model that an IGF-1R monoclonal antibody enhances the antitumor activity of tamoxifen in ER-receptor-positive breast cancer xenografts (81).

In vitro study has shown that increased IGF-IR signaling interferes with the action of the HER-2 antibody trastuzumab in HER2 positive breast cancer cells (82). Unlike EGFR, several studies have reported that tamoxifen continues to suppress the IGF-1R level, even during the development of resistance (65).

Mechanism of resistance to tamoxifen associated with signaling proteins p130Cas and $c$-Src. The focal adhesion adapter protein p130 (p130Cas) also known as breast cancer anti-estrogen resistance 1 , is involved in different cellular process, including proliferation, survival, cell adhesion and migration as an adapter or scaffolding protein (83). High expression of p130Cas is associated with resistance to tamoxifen and promotes the proliferation and inhibition of apoptosis in MCF-7 cells and in human tumors (84). Interactions between c-Src and p130Cas result in activation of c-Src activity, promotion of serum- and anchorage-independent growth and enhancement of cellular migration; concomitantly Cas is phosphorylated and activated by c-Src (83).

Two substrates of c-Src, tyrosine 845 (Tyr-845) on the EGFR and signal transducer and activator of transcription $5 b$ (STAT 5b) (85), have been implicated in p130Cas-dependent tamoxifen resistance (86). Pharmacologic inhibition of c-Src in MCF-7 cells enhances the inhibitory effects of tamoxifen on cell growth (86). It is clear that p130Cas overexpression diminishes the antiproliferative and pro-apoptotic effects of tamoxifen on breast cancer cells in vitro, and data suggest that it accomplishes this via activation of the p130Cas/c-Src/ EGFR/STAT5 signaling pathway. Whether these pathways are also clinically significant in resistance to tamoxifen has not yet been established; however, a large percentage of human breast tumors expresses high levels of both c-Src and p130Cas, as well as elevated c-Src kinase activity, and c-Src/Cas complexes can be isolated from a majority of breast cancer cell lines (3).
Taken together, these data suggest that tamoxifen resistance may be mediated in part through this mechanism involving c-Src and p130Cas.

Breast cancer anti-estrogen resistance 3 (BCAR3) protein. BCAR3 is a member of the novel Src homology 2 (SH2)containing protein family (87) that includes two other members, Chat/SHEP1 and NSP1. These proteins share a common domain structure consisting of an amino-terminal SH2 domain and a carboxyl-terminal domain with sequence homology to the Cdc25-family of guanine nucleotide exchange factors (GEF). Several studies have shown that BCAR3 expression results in the activation of numerous small GTPases, including Rap1, R-Ras, RalA, Cdc42 and Rac1 $(88,89)$. The carboxylterminal domain of BCAR3 has been shown to bind to the carboxyl terminus of p130Cas, providing additional support for a functional relationship between these proteins (88).

BCAR3 was discovered in a genetic screening for genes associated with anti-estrogen resistance and cell motility (90). It encodes a component of intracellular signal transduction and interacts directly with p130Cas. It has been demonstrated that breast cancer cells transfected with BCAR3 to induce anti-estrogen resistance, suggesting that upregulation of BCAR3 stimulates an alternative growth path independent of hormone, both in the presence and absence of anti-estrogens by activating PI3K, which induced Rac activation (91).

$P I 3 K$ and AKT pathway. The PI3K pathway is a key signal transduction system that links oncogenes and multiple receptor classes to many essential cellular functions, promotes anti-estrogen resistance and is perhaps the most commonly activated signaling pathway in human cancer (92-94). Studies have found that overexpression of HER2 or FGF-1R, or loss of the inositol polyphosphate phosphatase 4B (INPP4B), activate the PI3K pathway and also confer anti-estrogen resistance in patients with $\mathrm{ER}^{+}$breast cancer (95).

$\mathrm{PI} 3 \mathrm{~K}$ is commonly activated in breast cancer cells by growth factor receptor tyrosine kinases or G-protein-coupled receptors. The signaling cascades triggered by PI3K, including PDK1, AKT and SGK among others, promote cell growth and survival (94). PI3K phosphorylates phosphatidylinositol 4,5-bisphosphate $\left(\mathrm{PIP}_{2}\right)$ to produce phosphatidylinositol 3,4,5-trisphosphate $\left(\mathrm{PIP}_{3}\right)(96)$. In turn, $\mathrm{PIP}_{2}$ recruits several pleckstrin homology $(\mathrm{PH})$ domain-containing proteins to the plasma membrane such as the serine/threonine-protein kinase PDK1 and AKT, which on activation drive cell-cycle progression and survival. Negative regulation of this pathway is conferred by the tumor suppressors phosphatase and tensin homolog (PTEN) and INPP4B, which are lipid phosphatases and dephosphorylate $\mathrm{PIP}_{3}$ and $\mathrm{PIP}_{2}$, respectively $(32,97)$.

AKT activates mTOR-containing complex 1 (TORC1), which regulates protein synthesis. mTOR is also part of another complex, TORC2, which lies upstream of AKT. In addition to its pro-survival and growth-promoting roles, the PI3K pathway interacts with ER directly and indirectly. ER phosphorylation at $\operatorname{Ser}_{167}$ by AKT or p70S6K increases estrogen-induced, tamoxifen-induced, and ligand-independent ER transcriptional activity (74). Additionally, PI3K and Ras promote c-Jun phosphorylation. c-Jun complexes with c-Fos to form the AP-1 complex, which cooperates with ER tran- 
scription. Other oncogenic kinase pathways (MAPK, protein kinase C) also contribute to the modulation of ER and transcription cofactors (98).

Stress-activated protein kinase/c-Junkinase pathway.Estrogens induce apoptosis by regulating the c-Jun NH2-terminal kinases (JNKs). JNKs are stimulated by multiple factors, including cytokines, DNA-damaging agents, and environment stress, and are important in controlling apoptosis in the process of cellular stress, increasing AP-1 transcriptional activity via phosphorylation. AP-1 is a transcription factor heterodimer composed of Jun and Fos family members and binds to DNA at AP-1 response elements. It has been reported that the development of tamoxifen resistance in MCF-7 cells is accompanied by increased AP-1 DNA binding (99).

These findings have been examined in a panel of 30 ER-positive primary human breast tumors with acquired tamoxifen resistance, and these tumors also displayed a significant increase in AP-1 DNA binding activity when compared with untreated control tumor. In a tamoxifen-resistant xenograft model, increased phosphorylated c-Jun and JNK levels accompanied the increase in AP-1-dependent transcription following tamoxifen treatment, and the conversion to a resistant phenotype was associated with an increase in oxidative stress (OS) (100).

Cell cycle regulators associated with resistance to tamoxifen. Cyclins, cyclin-dependent kinases (CDKs) and CDK inhibitors are the major regulators of cell cycle progression (3). Estrogen accelerates progression from $\mathrm{G} 1$ to $\mathrm{S}$ phase, while tamoxifen inhibits cell cycle progression by affecting these key cell cycle proteins (101). The expression and activity of these proteins have been demonstrated to have the potential to significantly impact tamoxifen sensitivity and resistance.

Cyclin D1 plays an important role in the regulation of cell cycle, promoting progression through to G1-S phase. In mammary epithelial cells, the expression of cyclin D1 is regulated through the ER signaling (102). Cyclin D1 is a direct transcriptional target of estrogen signaling; thus, tamoxifen reduces cyclin D1 expression (103). In vitro sustained expression of cyclin D1 is evident in breast cancer cells during their acquisition of tamoxifen resistance, and downregulation of cyclin D1 with siRNA restored the sensitivity of these cells to tamoxifen (103). Cyclin D1 is one co-regulator, known to interact with $\mathrm{ER} \alpha$ and can potentiate its transcriptional activity independently of estrogen and may not be inhibited by tamoxifen (104). Overexpression of cyclin D1 has been reported to result in a conformational change in $\mathrm{ER} \alpha$ that induces receptor activation in the presence of tamoxifen, which in turn promotes growth of MCF-7 cells-indicating a change from antagonist to agonist $(105,106)$. Patients with cyclin D1 negative tumors show better relapse-free survival when they are treated with tamoxifen (107), whereas multiple clinical studies have demonstrated that overexpression of cyclin D1 is correlated with poor outcome on tamoxifen treatment $(107,108)$.

Cyclin D1 inhibits Rb early in G1 phase, and the transcription factor E2F strongly induces the expression of cyclin E, which is associated with CDK2 to form an active complex that promotes entry into $S$ phase (108). Cyclin E2 expression has been associated with poor outcome in ER-positive breast cancer (109), and cyclin E2 is included in genes that predict disease progression in either tamoxifen-resistant breast cancer or metastatic breast cancer, whereas cyclin E1 is absent $(110,111)$. Cyclin E1 overexpression can reduce antiestrogen sensitivity in vitro $(112,113)$, but cyclin E2 has not been studied in this context, although it is strongly estrogen regulated (114). In addition, CDK2 activation is a possible mechanism of resistance to a CDK4 inhibitor that preferentially inhibits ER-positive breast cancer cell lines and can overcome acquired resistance to tamoxifen $(115,116)$. We therefore considered cyclin E1 and E2 to be most important in anti-estrogen resistance in ER-positive breast cancer and potential therapeutic targets in endocrine-resistant disease.

Cell cycle progression upon ligand binding of ER has been shown to be mediated by cyclin/cyclin-dependent kinase (CDK) complexes and CDK inhibitors $(117,118)$. p21 is a member of the Cip/Kip family of CDK inhibitors and acts as a $G_{1}$ checkpoint protein, preventing cell cycle progression into $\mathrm{S}$ phase. $\mathrm{p} 21$ functions as a downstream effector of $\mathrm{p} 53$, and loss of p21 expression is seen in a high percentage of human breast cancers (117-119). p21 and p27 are CDK inhibitors and are negative regulators of cell cycle progression. These proteins counteract the activities of cyclin D1 and E. Expression of the ER, a good prognostic factor in breast cancer, is associated with higher levels of both p21 and p27 proteins $(120,121)$.

p27 induction in breast cancer cells by tamoxifen induces quiescence and clinical data also support a role of these CDK inhibitors in response to tamoxifen treatment. In premenopausal women with early breast cancer, an increase in p27/KIP1 expression was able to predict better relapse-free survival upon tamoxifen combination treatment (122).

Studies using immortalized human breast epithelial cells with somatic deletion of the p21 gene showed a growth proliferative response to tamoxifen as absence of p21 enabled cyclin-CDK complexes to aberrantly phosphorylate ER when bound to tamoxifen, resulting in a growth-stimulatory phenotype. On the other hand, p21 wild-type cells demonstrated growth inhibition upon tamoxifen exposure (123).

Bcl-2 family of proteins and their effect in resistance to tamoxifen. Deregulation of anti-apoptotic Bcl-2 family members, including Bcl-2, Bcl-xL and MCL-1, has been implicated in the progression of several different types of cancer. Studies have shown that initial expression of Bcl-2 correlates with ER expression, responsiveness to adjuvant hormonal therapy and ultimately a favorable prognosis (124). Several studies have also suggested that estrogen promotes resistance to chemotherapeutic drugs tamoxifen and cisplatin by increasing the Bcl-2: Bax ratio $(196,214)$. Also, in vitro studies in MCF-7 cells have shown that overexpression of HER-2 increases anti-apoptotic $\mathrm{Bcl}-2$ and $\mathrm{Bcl}-\mathrm{xL}$ proteins, leading to suppression of tamoxifen-induced apoptosis and ultimately tamoxifen resistance (50). Activation of the PI3K/Akt pathway causes phosphorylation of Bad leading to modulation of cellular apoptosis (125). Clinical studies have shown that high levels of Bad expression, not phosho-Bad levels, are associated with improved disease-free survival when compared to tumors with low levels of Bad expression (125).

Another important member of the Bcl2 family is BIK, which is inducible by estrogen-starvation and anti-estrogen 
treatment and plays an important role in anti-estrogen-induced apoptosis of breast cancer cells (126-128).

Our group has observed that Bik is a critical factor for resistance to tamoxifen, and utilizing MCF-7 cells has demonstrated that BIK mRNA and protein were strongly induced by estrogen-starvation or anti-estrogen treatment $(126,128)$. Conversely, knockdown of BIK by siRNA significantly inhibited the apoptosis caused by tamoxifen treatment, finding low expression of BAX, BAK and PUMA pro-apoptotic proteins and high expression of some anti-apoptotic proteins, such as BCL-2 and MCL-1 in BIK siRNA-transfected cells after treatment with TAM $(26,27)$. These data demonstrated that Bik is an important factor in the TAM-induced apoptosis process, which may regulate mitochondrial integrity by modulation of pro- and anti-apoptotic proteins. Our results showed that suppression of the BIK gene exhibited anti-apoptotic effects in TAM-treated MCF-7 cells. These data may be useful for future studies to establish the mechanisms of regulation of TAM resistance in breast cancer. In women with this neoplasm and with positive $\mathrm{ER}$, it may be important to determine BIK protein levels to define whether or not TAM is the appropriate treatment (128). A possible mechanism of resistance to apoptosis has been established and has been described using mouse fibroblasts transformed with v-src as a model. This group demonstrated that Src-dependent resistance to cell death relies on Src ability to inhibit the mitochondrial pathway of apoptosis by specifically increasing the degradation rate of the $\mathrm{BH} 3$-only protein Bik by proteasome due to the phosphorylation of Bik. This effect relies on the activation of the Ras-Raf-Mek1/2-Erk1/2 pathway and on the phosphorylation of Bik on Thr124, driving Bik ubiquitylation on Lys33 and subsequent degradation by the proteasome. These results suggest that Bik could be a rate-limiting factor for apoptosis induction of tumor cells exhibiting deregulated Erk1/2 signaling, which may provide new opportunities for cancer therapies (129).

Role for autophagy in anti-estrogen resistance. Recent studies have demonstrated that autophagy (also referred to as macroautophagy) is critical to the development of anti-estrogen resistance (130). This pro-survival role for autophagy in anti-estrogen-treated breast cancer cells is consistent with one function of the autophagosomes, which is to recycle metabolites from degraded cellular constituents to support a basal level of cell maintenance under starvation conditions and OS, thus rendering it essential for cellular viability.

The mammalian target of rapamycin (mTOR) kinase represents the major negative regulator of autophagy in human cells. Under physiological conditions, mTOR prevents autophagy by maintaining the hyperphosphorylation of the proteins required for the initiation of the autophagic cascade. Conversely, mTOR activity is rapidly shut down under conditions of stress, which allows for the rapid upregulation of autophagy (131). mTOR participates in multiple signaling cascades that regulate cell growth, and especially in those emanating from receptor tyrosine kinases (RTKs). In cancer cells, constitutively active RTK and/or the production of autocrine growth factors lead to the hyperphosphorylation of mTOR substrates. Moreover, several tumors are characterized by activating mutations of the key signal transducers connecting RTK to mTOR, including the small GTPase Ras, phosphatidylinositol 3-kinase (PI3K), as well as the Akt1 kinases and 3-phosphoinositide dependent protein kinase 1 (PDPK1) $(132,133)$. The essential autophagy regulator beclin 1 interacts with several cofactors (including Ambra1, Bif-1 and UVRAG) to activate the lipid kinase $\mathrm{Vps} 34$, which is required for the initiation of the autophagic pathway (134).

Beclin 1 is a haploin-sufficient tumor suppressor containing a BH3 domain that contributes to its interaction with BCL-2, but the avidity of this interaction is quite weak compared with the $\mathrm{BH} 3$ domains present in the $\mathrm{BH} 3$-only proteins typically associated with apoptosis regulation (135). Moreover, BH3-containing Beclin 1 does not appear to antagonize the anti-apoptotic function of BCL-2 at either the ER or mitochondria (136). Thus, canonical BH3-only proteins such as BAD have been shown to displace Beclin 1 from BCL-2 (137), leading to the proposal that an analogous signaling cascade to that associated with the release of BCL-2 antagonists by $\mathrm{BH} 3$-only proteins in the apoptosis pathway also extends to autophagy (138). BIK is the founding member of the BH3-only family proteins (139). A number of reports have shown that ectopic overexpression of BIK results in apoptotic cell death. However, BIK has also been reported to cause non-apoptotic cell death in human malignant glioma (140), melanoma cells (141) and in samples of human breast cancer (142), which could be associated with a mechanism of autophagy.

Another important member in autophagy is Vps34, which has a pro-survival function and increased Vps34 expression levels, and tyrosine phosphorylation by pp60c-Scr contributes to enhanced tumorigenic activity in breast cancer cells (143). In MCF-7 cells, knockdown of Vps34 by RNA interference reduced cytoprotective autophagy mediated by $\mathrm{BH} 3$ domain and potentiated apoptosis induction (144). Lastly, Vps34 possesses a tumor suppressor function in MCF-7 mouse xenograft tumors mediated through distinct Beclin-1 binding and enhancement of starvation-induced autophagy (145). These studies corroborate lines of evidence demonstrating that the PI3K/AKT/mTOR pathway, implicated in cell survival, contributes to anti-estrogen resistance (146). In contrast, our studies have identified loss of Vps15 and Raptor as the candidate gene target for mediating breast cancer tamoxifen resistance in vitro, suggesting that Vps15- or Raptor mediated autophagy promotes cell death induced by tamoxifen. In support of this suggestion, inhibitors of PI3K, Akt and mTOR are in clinical trials and inhibition of MTOR activity is thought to restore tamoxifen sensitivity in breast cancer (147).

miRNA. Recent studies have also shown the critical role of miRNAs in conferring drug resistance or responsiveness in cancer $(148,149)$. In breast cancer, the role of miRNAs in tamoxifen resistance, through regulation of cell cycle regulatory proteins, has been suggested. In particular, ectopic expression of miR-101, miR-206 and miR-221/miR-222 was found to render ER-positive MCF-7 cells resistant to tamoxifen (150-153). These miRNAs were also found to be significantly increased in Her2-positive primary human breast cancer tissues indicating an interrelationship between miR-221/222 expression and Her2 overexpression in primary breast tumors that are generally resistant to tamoxifen therapy. In tamoxifen-resistant breast cancer, it has been shown that miRNA-221/222 play a critical role in the development of 
resistance by targeting p27/kip1, a cell cycle inhibitor (153). When miRNA-221/222 downregulate p27/kip1, p27/kip1 can no longer bind to the CDK2/cyclin-E complex, allowing the cells to progress through cell cycle and facilitating growth of cancerous cells, even when estrogen receptors are blocked by tamoxifen (153).

miRNA-mediated targeting of ER $\alpha$ cofactors, which influence agonistic and antagonistic effects of ligand binding, has also been linked to impaired chemotherapeutic response. Indeed, one of the major co-activators for $\mathrm{ER} \alpha, \mathrm{AIB} 1$, is a target for miR-17 and miR-106, which are found to be dysregulated in breast cancer cells exhibiting drug resistance $(154,155)$. The transcriptional co-repressor, receptor interacting protein 140 (RIP140), was found to be targeted by miR-346, which is downregulated in endocrine-resistant cell lines (156), indicating a role for miRNAs in regulating estrogen-responsive genes.

\section{Signaling pathways that regulate EMT in tumor microenvironment}

The tubular EMT (TEMT)-related signaling associated with endocrine resistance are WNT, nuclear factor- $\kappa \beta(\mathrm{NF} \kappa \beta)$, Notch, keratinocyte growth factor (KGF), the platelet-derived growth factor (PDGF)/Abl signaling pathway and enolase-1.

Wnt signaling pathway is an important developmental pathway that is frequently dysregulated in human cancers including breast cancer (157-160). Wnt signaling is important for cell migration, invasion, adhesion and survival. Wnt ligands primarily signal via membrane bound Frizzled receptors through a number of different but interconnected signaling pathways, including the $\beta$-catenin, $\mathrm{Wnt} / \mathrm{Ca}^{2+}$, and planar-cell polarity pathways $(1,161)$. Wnt signaling is altered in nearly one half of all breast cancers. Both upregulation of Wnt pathway activators and downregulation of pathway inhibitors have been identified in breast cancer. Previous studies have reported that the activity of $\beta$-catenin is altered in acquired tamoxifen-resistant (TamR) breast cancer cells compared to endocrine-sensitive parental MCF7 cells, with an increase in $\beta$-catenin-mediated gene transcription. These observations suggest that deregulated Wnt signaling may play a role in acquired tamoxifen resistance in breast cancer where it may act to promote growth and the development of a more aggressive phenotype.

Keratinocyte growth factor/fibroblast growth factor-7 (KGF/FGF-7) is a member of the FGF family, which interacts with fibroblast growth factor receptors (FGFRs). KGF has a stromal origin and appears to act specifically on epithelial cells in human tissue and is therefore an exclusively paracrine growth factor in human tissues $(162,163)$. KGF stimulates normal human breast and human breast cancer epithelial cell proliferation in a dose-dependent manner. KGF may increase endocrine resistance via decreasing ER, progesterone receptor (PR) and protein tyrosine phosphatases $\gamma$ (PTP $\gamma)$. Results suggested that the presence of ER and PR is a good prognostic factor and indicator of benefit from endocrine therapy. Low levels of ER and PR in human breast cancers have been associated with resistance to tamoxifen and increased risk of breast cancer. The signal transduction of $\mathrm{KGF} / \mathrm{KGFR}$ can proceed via the Ras/MAPK and PI3K/
Akt pathways $(164,165)$. The findings on KGF stimulation of cell proliferation and motility via Ras/MAPK suggest that $\mathrm{KGF} / \mathrm{KGFR}$ could potentially influence the development and progression of breast cancer (166).

The Notch pathway has been reported to be involved in drug resistance. Studies have demonstrated that Notch regulates the formation of cancer stem cells (CSCs) and contributes to EMT leading to the acquisition of the invasive phenotype, which are associated with drug resistance $(167,168)$.

The Notch pathway is implicated in both cell fate in normal human mammary gland and regulation of CSCs in both ductal carcinoma in situ and invasive carcinoma of the breast (169-171). Binding of Notch ligand (Jagged or $\Delta$ ) to the Notch receptor cleaves its intracellular domain (NICD), which translocates to the nucleus where it binds with co-activators to induce transcription of its target genes and regulates migration and invasion of breast cancer cells. Estradiol inhibits Notch activity and affects Notch receptor cellular distribution. Tamoxifen and raloxifene block this effect, reactivating the Notch pathway. Pharmacologic inhibition of Notch activation with $\gamma$-secretase inhibitors (GSI) was more effective in combination with tamoxifen than tamoxifen alone (172). These data indicate that GSIs block the proliferative effect of tamoxifen through the Notch pathway, and at the same time allow tamoxifen to exert its antagonistic effect. In a previous study, Rizzo et al found that downregulation of Notch-1 by siRNA or GSI potentiated the effects of tamoxifen in breast cancer cells. Moreover, GSI in combination with tamoxifen caused regression of breast cancer cell growth in mice. These data indicate that the combinations of tamoxifen and Notch inhibitors may be effective in $\mathrm{ER} \alpha(+)$ breast cancer, and such a combination treatment could eliminate the emergence of tamoxifen-resistance $(172,173)$.

PDGF/Ableson (Abl) canonical signaling pathway has also been associated with resistance (174). PDGF receptor (PDGFR) is classified as a TRK whose activation is dependent on the binding of PDGF resulting in stimulation of several intracellular pathways. PDGF can promote tumor growth via autocrine stimulation of malignant cells, overexpression or overactivation of PDGFRs, or by stimulating tumor angiogenesis. Abl is an Src-like non-receptor protein kinase that acts downstream of the PDGFR (175). Its corresponding gene $c-A B L$ is a proto-oncogene with multiple functions; it regulates a variety of cellular activities, including cell migration, response to oxidative stress and DNA damage, cell proliferation and survival. Data revealed the PDGF/Abl canonical pathway as significantly upregulated as early as one-week post-estrogen deprivation and revealed that this could be the top adaptive pathway at the point of full resistance. In studies of molecular changes occurring in tumors in a cohort of patients treated with an aromatase inhibitor in the neoadjuvant setting, it was found that PDGFR $\beta$ expression was significantly associated with poor antiproliferative response to therapy (176).

$\alpha$-enolase (ENO1) is a glycolytic enzyme that converts 2-phosphoglycerate into phosphoenolpyruvate in glycolysis and a multifunctional protein that plays a crucial role in a variety of biological and pathophysiological processes (177). ENO1 may act as a stress protein that promotes hypoxic tolerance in tumor cells by increasing anaerobic metabolism (178). ENO1 may also function as a plasminogen receptor on the 
surface of a variety of hematopoetic, epithelial, endothelial and cancerous cells $(179,180)$. Previously, several lines of evidence suggested that ENO1 may contribute to tumor malignancy (180). Upregulation of the ENOI gene has been observed in several highly tumorigenic or metastatic cell lines $(181,182)$ and its enzymatic activity in breast cancer suggests a role of ENO1 in tumor progression. Increased expression of enolase $\alpha$ in human breast cancer confers tamoxifen resistance in humans. The treatment with 4-OH tamoxifen-induced ENO-1 overexpression, which results in endocrine resistance in human breast cancer (MCF-7) cells. ENO-1 was induced by 4-OH tamoxifen treatment through transcriptional upregulation of ER $\alpha$ and NFKB. The enhanced expression of ENO-1 exerts a negative regulatory effect on c-Myc transcription that counteracts the 4-OH tamoxifen-induced apoptosis of breast cancer cells. In contrast, inhibition of ENO-1 transcriptional regulation, either by blocking the $\mathrm{NF \kappa B}$ signal pathway or by siRNA knockdown, significantly sensitized human breast cancer cells to 4-OH tamoxifen-induced cytotoxicity (183). These results suggest that ENO-1 may facilitate resistance to 4-OH tamoxifen-induced cell death and that the combined use of 4-OH tamoxifen and an NFאB pathway inhibitor (PDTC) may provide a novel approach to overcome tamoxifen resistance in breast cancer (184).

\section{Conclusion}

Endocrine treatment of ER-positive breast cancer with tamoxifen, and later with aromatase inhibitors and the estrogen receptor antagonist fulvestrant, are the first target-based therapeutic strategies in oncology. However, a substantial proportion of patients, despite being ER and/or PR-positive, are either primarily resistant or will develop resistance during the course of their disease. Delineation of the molecular mechanisms underlying the development of resistance will allow the development of therapeutic strategies to improve the efficiency of treatment and to prevent or overcome the drug resistance.

\section{Acknowledgements}

This study was performed in partial fulfillment of the requirements for the $\mathrm{PhD}$ degree in Biomedical Sciences of Rubí Viedma-Rodríguez at the Universidad Nacional Autónoma de México, with a doctoral fellowship provided by CONACyT-México (grant no. 207148). Supported, in part, by PAPIT-DGAPA-UNAM, grants IN 230611 and IN 223014 to Luis Baiza-Gutman.

\section{References}

1. Kohn AD and Moon RT: Wnt and calcium signaling: $\beta$-cateninindependent pathways. Cell Calcium 38: 439-446, 2005.

2. Deroo BJ and Korach KS: Estrogen receptors and human disease. J Clin Invest 116: 561-570, 2006.

3. Riggins RB, Schrecengost RS, Guerrero MS and Bouton AH: Pathways to tamoxifen resistance. Cancer Lett 256: 1-24, 2007.

4. Mueller SO and Korach KS: Estrogen receptors and endocrine diseases: lessons from estrogen receptor knockout mice. Curr Opin Pharmacol 1: 613-619, 2001.

5. Henderson BE and Feigelson HS: Hormonal carcinogenesis. Carcinogenesis 21: 427-433, 2000.

6. Kuiper GG, Enmark E, Pelto-Huikko M, Nilsson S and Gustafsson JA: Cloning of a novel receptor expressed in rat prostate and ovary. Proc Natl Acad Sci USA 93: 5925-5930, 1996.
7. Mosselman S, Polman J and Dijkema R: ER $\beta$ : identification and characterization of a novel human estrogen receptor. FEBS Lett 392: 49-53, 1996.

8. Dixon D, Couse JF and Korach KS: Disruption of the estrogen receptor gene in mice. Toxicol Pathol 25: 518-520, 1997.

9. Elliston JF, Fawell SE, Klein-Hitpass L, et al: Mechanism of estrogen receptor-dependent transcription in a cell-free system. Mol Cell Biol 10: 6607-6612, 1990.

10. Frasor J, Danes JM, Komm B, Chang KC, Lyttle CR and Katzenellenbogen BS: Profiling of estrogen up- and down-regulated gene expression in human breast cancer cells: insights into gene networks and pathways underlying estrogenic control of proliferation and cell phenotype. Endocrinology 144: 4562-4574, 2003.

11. Webb P, Lopez GN, Uht RM and Kushner PJ: Tamoxifen activation of the estrogen receptor/AP-1 pathway: potential origin for the cell-specific estrogen-like effects of antiestrogens. Mol Endocrinol 9: 443-456, 1995.

12. Kushner PJ, Agard DA, Greene GL, et al: Estrogen receptor pathways to AP-1. J Steroid Biochem Mol Biol 74: 311-317, 2000.

13. Smith CL and O'Malley BW: Coregulator function: a key to understanding tissue specificity of selective receptor modulators. Endocr Rev 25: 45-71, 2004.

14. Osborne CK, Bardou V, Hopp TA, et al: Role of the estrogen receptor coactivator AIB1 (SRC-3) and HER-2/neu in tamoxifen resistance in breast cancer. J Natl Cancer Inst 95: 353-361, 2003.

15. Saville B, Wormke M, Wang F, et al: Ligand-, cell-, and estrogen receptor subtype $(\alpha / \beta)$-dependent activation at GC-rich (Sp1) promoter elements. J Biol Chem 275: 5379-5387, 2000.

16. Kelloff GJ, Lippman SM, Dannenberg AJ, et al: Progress in chemoprevention drug development: the promise of molecular biomarkers for prevention of intraepithelial neoplasia and cancer - a plan to move forward. Clin Cancer Res 12: 3661-3697, 2006.

17. Schiff R, Massarweh SA, Shou J, Bharwani L, Mohsin SK and Osborne CK: Cross-talk between estrogen receptor and growth factor pathways as a molecular target for overcoming endocrine resistance. Clin Cancer Res 10: 331S-336S, 2004.

18. Le Goff P, Montano MM, Schodin DJ and Katzenellenbogen BS: Phosphorylation of the human estrogen receptor. Identification of hormone-regulated sites and examination of their influence on transcriptional activity. J Biol Chem 269: 4458-4466, 1994.

19. Vyhlidal C, Samudio I, Kladde MP and Safe S: Transcriptional activation of transforming growth factor $\alpha$ by estradiol: requirement for both a GC-rich site and an estrogen response element half-site. J Mol Endocrinol 24: 329-338, 2000.

20. Lee AV, Cui X and Oesterreich S: Cross-talk among estrogen receptor, epidermal growth factor, and insulin-like growth factor signaling in breast cancer. Clin Cancer Res 7 (Suppl 12): S4429-S4435, 2001.

21. Yarden RI, Wilson MA and Chrysogelos SA: Estrogen suppression of EGFR expression in breast cancer cells: a possible mechanism to modulate growth. J Cell Biochem (Suppl 36): 232-246, 2001.

22. Bayliss J, Hilger A, Vishnu P, Diehl K and El-Ashry D: Reversal of the estrogen receptor negative phenotype in breast cancer and restoration of antiestrogen response. Clin Cancer Res 13: 7029-7036, 2007.

23. Cui X, Zhang P, Deng W, et al: Insulin-like growth factor-I inhibits progesterone receptor expression in breast cancer cells via the phosphatidylinositol 3-kinase/Akt/mammalian target of rapamycin pathway: progesterone receptor as a potential indicator of growth factor activity in breast cancer. Mol Endocrinol 17: 575-588, 2003.

24. Brinkman JA and El-Ashry D: ER re-expression and re-sensitization to endocrine therapies in ER-negative breast cancers. J Mammary Gland Biol Neoplasia 14: 67-78, 2009.

25. Levin ER and Pietras RJ: Estrogen receptors outside the nucleus in breast cancer. Breast Cancer Res Treat 108: 351-361, 2008.

26. Pedram A, Razandi M, Lubahn D, Liu J, Vannan M and Levin ER: Estrogen inhibits cardiac hypertrophy: role of estrogen receptor- $\beta$ to inhibit calcineurin. Endocrinology 149: 3361-3369, 2008.

27. Wu RC, Qin J, Yi P, et al: Selective phosphorylations of the SRC-3/AIB1 coactivator integrate genomic reponses to multiple cellular signaling pathways. Mol Cell 15: 937-949, 2004.

28. Pontiggia O, Rodriguez V, Fabris V, et al: Establishment of an in vitro estrogen-dependent mouse mammary tumor model: a new tool to understand estrogen responsiveness and development of tamoxifen resistance in the context of stromal-epithelial interactions. Breast Cancer Res Treat 116: 247-255, 2009. 
29. Machuca TN, Hsin MK, Ott HC, et al: Injury-specific ex vivo treatment of the donor lung: pulmonary thrombolysis followed by successful lung transplantation. Am J Respir Crit Care Med 188: 878-880, 2013

30. Goetz MP, Rae JM, Suman VJ, et al: Pharmacogenetics of tamoxifen biotransformation is associated with clinical outcomes of efficacy and hot flashes. J Clin Oncol 23: 9312-9318, 2005

31. Stearns V and Rae JM: Pharmacogenetics and breast cancer endocrine therapy: CYP2D6 as a predictive factor for tamoxifen metabolism and drug response? Expert Rev Mol Med 10: e34, 2008.

32. Jaiswal BS, Janakiraman V, Kljavin NM, et al: Somatic mutations in $\mathrm{p} 85 \alpha$ promote tumorigenesis through class IA PI3K activation. Cancer Cell 16: 463-474, 2009.

33. Madeira M, Mattar A, Logullo AF, Soares FA and Gebrim LH: Estrogen receptor alpha/beta ratio and estrogen receptor beta as predictors of endocrine therapy responsiveness-a randomized neoadjuvant trial comparison between anastrozole and tamoxifen for the treatment of postmenopausal breast cancer. BMC Cancer 13: 425, 2013.

34. McGuire WL: Current status of estrogen receptors in human breast cancer. Cancer 36: 638-644, 1975.

35. Esslimani-Sahla M, Simony-Lafontaine J, Kramar A, et al: Estrogen receptor $\beta$ (ER $\beta)$ level but not its ER $\beta c x$ variant helps to predict tamoxifen resistance in breast cancer. Clin Cancer Res 10: 5769-5776, 2004

36. Hopp TA, Weiss HL, Parra IS, Cui Y, Osborne CK and Fuqua SA: Low levels of estrogen receptor $\beta$ protein predict resistance to tamoxifen therapy in breast cancer. Clin Cancer Res 10: 7490-7499, 2004.

37. Kuiper GG, Lemmen JG, Carlsson B, et al: Interaction of estrogenic chemicals and phytoestrogens with estrogen receptor $\beta$. Endocrinology 139: 4252-4263, 1998

38. Yang X, Phillips DL, Ferguson AT, Nelson WG, Herman JG and Davidson NE: Synergistic activation of functional estrogen receptor (ER)- $\alpha$ by DNA methyltransferase and histone deacetylase inhibition in human ER- $\alpha$-negative breast cancer cells. Cancer Res 61: 7025-7029, 2001.

39. Parl FF: Multiple mechanisms of estrogen receptor gene repression contribute to ER-negative breast cancer. Pharmacogenomics J 3: 251-253, 2003.

40. Ottaviano YL, Issa JP, Parl FF, Smith HS, Baylin SB and Davidson NE: Methylation of the estrogen receptor gene CpG island marks loss of estrogen receptor expression in human breast cancer cells. Cancer Res 54: 2552-2555, 1994

41. Robertson KD, Ait-Si-Ali S, Yokochi T, Wade PA, Jones PL and Wolffe AP: DNMT1 forms a complex with Rb, E2F1 and HDAC1 and represses transcription from E2F-responsive promoters. Nat Genet 25: 338-342, 2000.

42. Fan J, Yin WJ, Lu JS, et al: ERa negative breast cancer cells restore response to endocrine therapy by combination treatment with both HDAC inhibitor and DNMT inhibitor. J Cancer Res Clin Oncol 134: 883-890, 2008.

43. Zhou Q, Shaw PG and Davidson NE: Inhibition of histone deacetylase suppresses EGF signaling pathways by destabilizing EGFR mRNA in ER-negative human breast cancer cells. Breast Cancer Res Treat 117: 443-451, 2009.

44. Sabnis GJ, Goloubeva O, Chumsri S, Nguyen N, Sukumar S and Brodie AM: Functional activation of the estrogen receptor- $\alpha$ and aromatase by the HDAC inhibitor entinostat sensitizes ER-negative tumors to letrozole. Cancer Res 71: 1893-1903, 2011.

45. Mahfoudi A, Roulet E, Dauvois S, Parker MG and Wahli W: Specific mutations in the estrogen receptor change the properties of antiestrogens to full agonists. Proc Natl Acad Sci USA 92 4206-4210, 1995.

46. Wolf DM and Jordan VC: The estrogen receptor from a tamoxifen stimulated MCF-7 tumor variant contains a point mutation in the ligand binding domain. Breast Cancer Res Treat 31: 129-138, 1994.

47. MacGregor Schafer J, Liu H, Bentrem DJ, Zapf JW and Jordan VC: Allosteric silencing of activating function 1 in the 4-hydroxytamoxifen estrogen receptor complex is induced by substituting glycine for aspartate at amino acid 351. Cancer Res 60: 5097-5105, 2000

48. Thomas RS, Sarwar N, Phoenix F, Coombes RC and Ali S: Phosphorylation at serines 104 and 106 by Erk1/2 MAPK is important for estrogen receptor- $\alpha$ activity. J Mol Endocrinol 40 : 173-184, 2008.
49. Chen D, Washbrook E, Sarwar N, et al: Phosphorylation of human estrogen receptor $\alpha$ at serine 118 by two distinct signal transduction pathways revealed by phosphorylation-specific antisera. Oncogene 21: 4921-4931, 2002.

50. Williams CC, Basu A, El-Gharbawy A, Carrier LM, Smith CL and Rowan BG: Identification of four novel phosphorylation sites in estrogen receptor $\alpha$ : impact on receptor-dependent gene expression and phosphorylation by protein kinase CK2. BMC Biochem 10: 36, 2009

51. Rogatsky I, Trowbridge JM and Garabedian MJ: Potentiation of human estrogen receptor $\alpha$ transcriptional activation through phosphorylation of serines 104 and 106 by the cyclin A-CDK2 complex. J Biol Chem 274: 22296-22302, 1999.

52. Michalides R, van Tinteren H, Balkenende A, et al: Cyclin A is a prognostic indicator in early stage breast cancer with and without tamoxifen treatment. Br J Cancer 86: 402-408, 2002.

53. Vendrell JA, Bieche I, Desmetz C, et al: Molecular changes associated with the agonist activity of hydroxy-tamoxifen and the hyper-response to estradiol in hydroxy-tamoxifen-resistant breast cancer cell lines. Endocr Relat Cancer 12: 75-92, 2005.

54. Likhite VS, Stossi F, Kim K, Katzenellenbogen BS and Katzenellenbogen JA: Kinase-specific phosphorylation of the estrogen receptor changes receptor interactions with ligand, deoxyribonucleic acid, and coregulators associated with alterations in estrogen and tamoxifen activity. Mol Endocrinol 20 3120-3132, 2006

55. Kato S, Endoh H, Masuhiro Y, et al: Activation of the estrogen receptor through phosphorylation by mitogen-activated protein kinase. Science 270: 1491-1494, 1995.

56. Barone I, Brusco L and Fuqua SA: Estrogen receptor mutations and changes in downstream gene expression and signaling. Clin Cancer Res 16: 2702-2708, 2010.

57. de Leeuw R, Neefjes J and Michalides R: A role for estrogen receptor phosphorylation in the resistance to tamoxifen. Int J Breast Cancer 2011: 232435, 2011

58. Osborne CK and Schiff R: Estrogen-receptor biology: continuing progress and therapeutic implications. J Clin Oncol 23: 1616-1622, 2005.

59. Girault I, Bièche I and Lidereau R: Role of estrogen receptor $\alpha$ transcriptional coregulators in tamoxifen resistance in breast cancer. Maturitas 54: 342-351, 2006

60. Webb P, Nguyen P, Shinsako J, et al: Estrogen receptor activation function 1 works by binding p160 coactivator proteins. Mol Endocrinol 12: 1605-1618, 1998.

61. Kressler D, Hock MB and Kralli A: Coactivators PGC-1 $\beta$ and SRC-1 interact functionally to promote the agonist activity of the selective estrogen receptor modulator tamoxifen. J Biol Chem 282: 26897-26907, 2007.

62. Fuqua SA, Schiff R, Parra I, et al: Estrogen receptor $\beta$ protein in human breast cancer: correlation with clinical tumor parameters. Cancer Res 63: 2434-2439, 2003.

63. Lavinsky RM, Jepsen K, Heinzel T, et al: Diverse signaling pathways modulate nuclear receptor recruitment of $\mathrm{N}-\mathrm{CoR}$ and SMRT complexes. Proc Natl Acad Sci USA 95: 2920-2925, 1998.

64. Kurokawa H, Lenferink AE, Simpson JF, et al: Inhibition of HER2/neu (erbB-2) and mitogen-activated protein kinases enhances tamoxifen action against HER2-overexpressing, tamoxifen-resistant breast cancer cells. Cancer Res 60: 5887-5894, 2000.

65. Massarweh S, Osborne CK, Creighton CJ, et al: Tamoxifen resistance in breast tumors is driven by growth factor receptor signaling with repression of classic estrogen receptor genomic function. Cancer Res 68: 826-833, 2008.

66. Fagan DH, Uselman RR, Sachdev D and Yee D: Acquired resistance to tamoxifen is associated with loss of the type I insulin-like growth factor receptor: implications for breast cancer treatment. Cancer Res 72: 3372-3380, 2012.

67. Ciampolillo A, De Tullio C and Giorgino F: The IGF-I/IGF-I receptor pathway: implications in the pathophysiology of thyroid cancer. Curr Med Chem 12: 2881-2891, 2005

68. Lee AV, Weng CN, Jackson JG and Yee D: Activation of estrogen receptor-mediated gene transcription by IGF-I in human breast cancer cells. J Endocrinol 152: 39-47, 1997.

69. Fagan DH and Yee D: Crosstalk between IGF1R and estrogen receptor signaling in breast cancer. J Mammary Gland Biol Neoplasia 13: 423-429, 2008.

70. Lee AV, Darbre P and King RJ: Processing of insulin-like growth factor-II (IGF-II) by human breast cancer cells. Mol Cell Endocrinol 99: 211-220, 1994. 
71. Umayahara Y,Kawamori R, Watada H, et al: Estrogen regulation of the insulin-like growth factor I gene transcription involves an AP-1 enhancer. J Biol Chem 269: 16433-16442, 1994.

72. Salerno M, Sisci D, Mauro L, Guvakova MA, Ando S and Surmacz E: Insulin receptor substrate 1 is a target for the pure antiestrogen ICI 182,780 in breast cancer cells. Int J Cancer 81: 299-304, 1999

73. Becker MA, Ibrahim YH, Cui X, Lee AV and Yee D: The IGF pathway regulates $E R \alpha$ through a S6K1-dependent mechanism in breast cancer cells. Mol Endocrinol 25: 516-528, 2011.

74. Campbell RA, Bhat-Nakshatri P, Patel NM, Constantinidou D, Ali S and Nakshatri H: Phosphatidylinositol 3-kinase/AKTmediated activation of estrogen receptor $\alpha$ : a new model for anti-estrogen resistance. J Biol Chem 276: 9817-9824, 2001.

75. Ahn BY, Elwi AN, Lee B, et al: Genetic screen identifies insulinlike growth factor binding protein 5 as a modulator of tamoxifen resistance in breast cancer. Cancer Res 70: 3013-3019, 2010.

76. Beattie J, Allan GJ, Lochrie JD and Flint DJ: Insulin-like growth factor-binding protein-5 (IGFBP-5): a critical member of the IGF axis. Biochem J 395: 1-19, 2006.

77. Akkiprik M, Feng Y, Wang H, et al: Multifunctional roles of insulin-like growth factor binding protein 5 in breast cancer. Breast Cancer Res 10: 212, 2008.

78. Bunone G, Briand PA, Miksicek RJ and Picard D: Activation of the unliganded estrogen receptor by EGF involves the MAP kinase pathway and direct phosphorylation. EMBO J 15 : 2174-2183, 1996.

79. Parisot JP, Hu XF, DeLuise M and Zalcberg JR: Altered expression of the IGF-1 receptor in a tamoxifen-resistant human breast cancer cell line. Br J Cancer 79: 693-700, 1999.

80. Knowlden JM, Hutcheson IR, Barrow D, Gee JM and Nicholson RI: Insulin-like growth factor-I receptor signaling in tamoxifen-resistant breast cancer: a supporting role to the epidermal growth factor receptor. Endocrinology 146 : 4609-4618, 2005.

81. Cohen BD, Baker DA, Soderstrom C, et al: Combination therapy enhances the inhibition of tumor growth with the fully human anti-type 1 insulin-like growth factor receptor monoclonal antibody CP-751,871. Clin Cancer Res 11: 2063-2073, 2005.

82. Lu Y, Zi X, Zhao Y, Mascarenhas D and Pollak M: Insulin-like growth factor-I receptor signaling and resistance to trastuzumab (Herceptin). J Natl Cancer Inst 93: 1852-1857, 2001.

83. Bouton AH, Riggins RB and Bruce-Staskal PJ: Functions of the adapter protein Cas: signal convergence and the determination of cellular responses. Oncogene 20: 6448-6458, 2001.

84. Defilippi P, Di Stefano P and Cabodi S: p130Cas: a versatile scaffold in signaling networks. Trends Cell Biol 16: 257-263, 2006

85. Lu Y, Mani S, Kandimalla ER, et al: The Cockayne syndrome group B DNA repair protein as an anti-cancer target. Int J Oncol 19: 1089-1097, 2001.

86. Planas-Silva MD and Hamilton KN: Targeting c-Src kinase enhances tamoxifen's inhibitory effect on cell growth by modulating expression of cell cycle and survival proteins. Cancer Chemother Pharmacol 60: 535-543, 2007.

87. Schuh NR, Guerrero MS, Schrecengost RS and Bouton AH: BCAR3 regulates Src/p130 Cas association, Src kinase activity, and breast cancer adhesion signaling. J Biol Chem 285: 2309-2317, 2010

88. Gotoh T, Cai D, Tian X, Feig LA and Lerner A: p130 $0^{\text {Cas }}$ regulates the activity of AND-34, a novel Ral, Rap1, and R-Ras guanine nucleotide exchange factor. J Biol Chem 275: 30118-30123, 2000

89. Cai D, Iyer A, Felekkis KN, et al: AND-34/BCAR3, a GDP exchange factor whose overexpression confers antiestrogen resistance, activates Rac, PAK1, and the cyclin D1 promoter. Cancer Res 63: 6802-6808, 2003.

90. van Agthoven T, van Agthoven TL, Dekker A, van der Spek PJ, Vreede L and Dorssers LC: Identification of BCAR3 by a random search for genes involved in antiestrogen resistance of human breast cancer cells. EMBO J 17: 2799-2808, 1998.

91. Felekkis KN, Narsimhan RP, Near R, et al: AND-34 activates phosphatidylinositol 3-kinase and induces anti-estrogen resistance in a SH2 and GDP exchange factor-like domain-dependent manner. Mol Cancer Res 3: 32-41, 2005.

92. Liu P, Cheng H, Roberts TM and Zhao JJ: Targeting the phosphoinositide 3-kinase pathway in cancer. Nat Rev Drug Discov 8 : 627-644, 2009.

93. Miller TW, Balko JM and Arteaga CL: Phosphatidylinositol 3-kinase and antiestrogen resistance in breast cancer. J Clin Oncol 29: 4452-4461, 2011
94. Fox EM, Arteaga CL and Miller TW: Abrogating endocrine resistance by targeting ER $\alpha$ and PI3K in breast cancer. Front Oncol 2: 145, 2012.

95. Turner N, Pearson A, Sharpe R, et al: FGFR1 amplification drives endocrine therapy resistance and is a therapeutic target in breast cancer. Cancer Res 70: 2085-2094, 2010.

96. van der Kaay J, Cullen PJ and Downes CP: Phosphatidylinositol $(3,4,5)$ trisphosphate $\left(\operatorname{Ptdin} \mathrm{s}(3,4,5) \mathrm{P}_{3}\right)$ mass measurement using a radioligand displacement assay. Methods Mol Biol 105: 109-125, 1998

97. Maehama T and Dixon JE: The tumor suppressor, PTEN/ MMAC1, dephosphorylates the lipid second messenger, phosphatidylinositol 3,4,5-trisphosphate. J Biol Chem 273: 13375-13378, 1998

98. Massarweh S and Schiff R: Unraveling the mechanisms of endocrine resistance in breast cancer: new therapeutic opportunities. Clin Cancer Res 13: 1950-1954, 2007.

99. Lewis-Wambi JS and Jordan VC: Estrogen regulation of apoptosis: how can one hormone stimulate and inhibit? Breast Cancer Res 11: 206, 2009.

100. Schiff R, Reddy P, Ahotupa M, et al: Oxidative stress and AP-1 activity in tamoxifen-resistant breast tumors in vivo. $\mathrm{J}$ Natl Cancer Inst 92: 1926-1934, 2000.

101. Nair BC and Vadlamudi RK: Regulation of hormonal therapy resistance by cell cycle machinery. Gene Ther Mol Biol 12: 395, 2008.

102. Butt AJ, McNeil CM, Musgrove EA and Sutherland RL: Downstream targets of growth factor and oestrogen signalling and endocrine resistance: the potential roles of c-Myc, cyclin D1 and cyclin E. Endocr Relat Cancer 12 (Suppl 10): S47-S59, 2005.

103. Kilker RL, Hartl MW, Rutherford TM and Planas-Silva MD: Cyclin D1 expression is dependent on estrogen receptor function in tamoxifen-resistant breast cancer cells. J Steroid Biochem Mol Biol 92: 63-71, 2004.

104.Zwijsen RM, Wientjens E, Klompmaker R, van der Sman J, Bernards R and Michalides RJ: CDK-independent activation of estrogen receptor by cyclin D1. Cell 88: 405-415, 1997.

105. Wilcken NR, Prall OW, Musgrove EA and Sutherland RL: Inducible overexpression of cyclin D1 in breast cancer cells reverses the growth-inhibitory effects of antiestrogens. Clin Cancer Res 3: 849-854, 1997.

106. Osborne CK and Schiff R: Growth factor receptor cross-talk with estrogen receptor as a mechanism for tamoxifen resistance in breast cancer. Breast 12: 362-367, 2003.

107. Rudas M, Lehnert M, Huynh A, et al: Cyclin D1 expression in breast cancer patients receiving adjuvant tamoxifen-based therapy. Clin Cancer Res 14: 1767-1774, 2008.

108. Stendahl M, Kronblad A, Rydén L, Emdin S, Bengtsson NO and Landberg G: Cyclin D1 overexpression is a negative predictive factor for tamoxifen response in postmenopausal breast cancer patients. Br J Cancer 90: 1942-1948, 2004.

109. Sieuwerts AM, Look MP, Meijer-van Gelder ME, et al: Which cyclin E prevails as prognostic marker for breast cancer? Results from a retrospective study involving 635 lymph nodenegative breast cancer patients. Clin Cancer Res 12: 3319-3328, 2006.

110. Bosco EE, Wang Y, Xu H, et al: The retinoblastoma tumor suppressor modifies the therapeutic response of breast cancer. J Clin Invest 117: 218-228, 2007.

111. Musgrove EA, Sergio CM, Anderson LR, et al: Identification of downstream targets of estrogen and c-myc in breast cancer cells. Adv Exp Med Biol 617: 445-451, 2008.

112. Dhillon NK and Mudryj M: Ectopic expression of cyclin E in estrogen responsive cells abrogates antiestrogen mediated growth arrest. Oncogene 21: 4626-4634, 2002.

113. Hui R, Finney GL, Carroll JS, Lee CS, Musgrove EA and Sutherland RL: Constitutive overexpression of cyclin D1 but not cyclin E confers acute resistance to antiestrogens in T-47D breast cancer cells. Cancer Res 62: 6916-6923, 2002.

114. Caldon CE, Sergio CM, Schütte J, et al: Estrogen regulation of cyclin E2 requires cyclin D1 but not c-Myc. Mol Cell Biol 29: 4623-4639, 2009

115. Finn RS, Dering J, Conklin D, et al: PD 0332991, a selective cyclin D kinase $4 / 6$ inhibitor, preferentially inhibits proliferation of luminal estrogen receptor-positive human breast cancer cell lines in vitro. Breast Cancer Res 11: R77, 2009.

116. Wang L, Wang J, Blaser BW, et al: Pharmacologic inhibition of CDK4/6: mechanistic evidence for selective activity or acquired resistance in acute myeloid leukemia. Blood 110: 2075-2083, 2007. 
117. Planas-Silva MD and Weinberg RA: Estrogen-dependent cyclin E-cdk2 activation through p21 redistribution. Mol Cell Biol 17: 4059-4069, 1997.

118. Cariou S, Donovan JC, Flanagan WM, Milic A, Bhattacharya N and Slingerland JM: Down-regulation of $221^{\text {WAF1/CIP1 }}$ or $\mathrm{p} 27^{\mathrm{Kip}}$ abrogates antiestrogen-mediated cell cycle arrest in human breast cancer cells. Proc Natl Acad Sci USA 97: 9042-9046, 2000.

119. Bachman KE, Blair BG, Brenner K, et al: $\mathrm{p} 21^{\mathrm{WAF} 1 / \mathrm{CIP} 1}$ mediates the growth response to TGF- $\beta$ in human epithelial cells. Cancer Biol Ther 3: 221-225, 2004.

120. Mokbel K: The evolving role of aromatase inhibitors in breast cancer. Int J Clin Oncol 7: 279-283, 2002.

121. Jordan VC: Tamoxifen (ICI46,474) as a targeted therapy to treat and prevent breast cancer. Br J Pharmacol 147 (Suppl 1): S269-S276, 2006

122. Pohl G, Rudas M, Dietze O, et al: High p27 ${ }^{\text {Kip1 }}$ expression predicts superior relapse-free and overall survival for premenopausal women with early-stage breast cancer receiving adjuvant treatment with tamoxifen plus goserelin. J Clin Oncol 21: 3594-3600, 2003.

123. Abukhdeir AM and Park BH: P21 and p27: roles in carcinogenesis and drug resistance. Expert Rev Mol Med 10: e19, 2008

124. Ellis PA, Smith IE, Detre S, et al: Reduced apoptosis and proliferation and increased $\mathrm{Bcl}-2$ in residual breast cancer following preoperative chemotherapy. Breast Cancer Res Treat 48: 107-116, 1998

125. Cannings E, Kirkegaard T, Tovey SM, Dunne B, Cooke TG and Bartlett JM: Bad expression predicts outcome in patients treated with tamoxifen. Breast Cancer Res Treat 102: 173-179, 2007.

126. Hur J, Chesnes J, Coser KR, et al: The Bik BH3-only protein is induced in estrogen-starved and antiestrogen-exposed breast cancer cells and provokes apoptosis. Proc Natl Acad Sci USA 101: 2351-2356, 2004.

127. Fu Y, Li J and Lee AS: GRP78/BiP inhibits endoplasmic reticulum BIK and protects human breast cancer cells against estrogen starvation-induced apoptosis. Cancer Res 67:3734-3740, 2007.

128. Viedma-Rodriguez R, Baiza-Gutman LA, García-Carrancá A, Moreno-Fierros L, Salamanca-Gómez F and Arenas-Aranda D: Suppression of the death gene BIK is a critical factor for resistance to tamoxifen in MCF-7 breast cancer cells. Int J Oncol 43 1777-1786, 2013.

129. Lopez J, Hesling C, Prudent J, et al: Src tyrosine kinase inhibits apoptosis through the Erk1/2-dependent degradation of the death accelerator Bik. Cell Death Differ 19: 1459-1469, 2012 .

130. Schoenlein PV, Periyasamy-Thandavan S, Samaddar JS, Jackson WH and Barrett JT: Autophagy facilitates the progression of ER $\alpha$-positive breast cancer cells to antiestrogen resistance. Autophagy 5: 400-403, 2009.

131. Galluzzi L, Vicencio JM, Kepp O, Tasdemir E, Maiuri MC and Kroemer G: To die or not to die: that is the autophagic question. Curr Mol Med 8: 78-91, 2008

132. Cully M, You H, Levine AJ and Mak TW: Beyond PTEN mutations: the PI3K pathway as an integrator of multiple inputs during tumorigenesis. Nat Rev Cancer 6: 184-192, 2006.

133. Shaw RJ and Cantley LC: Ras, PI(3)K and mTOR signalling controls tumour cell growth. Nature 441: 424-430, 2006

134. Degenhardt K, Mathew R, Beaudoin B, et al: Autophagy promotes tumor cell survival and restricts necrosis, inflammation, and tumorigenesis. Cancer Cell 10: 51-64, 2006.

135. Feng W, Huang S, Wu H and Zhang M: Molecular basis of Bcl-xL's target recognition versatility revealed by the structure of Bcl-xL in complex with the BH3 domain of Beclin-1. J Mol Biol 372: 223-235, 2007.

136. Ciechomska IA, Goemans GC, Skepper JN and Tolkovsky AM: Bcl-2 complexed with Beclin-1 maintains full anti-apoptotic function. Oncogene 28: 2128-2141, 2009

137. Maiuri MC, Le Toumelin G, Criollo A, et al: Functional and physical interaction between $\mathrm{Bcl}-\mathrm{X}_{\mathrm{L}}$ and a $\mathrm{BH} 3$-like domain in Beclin-1. EMBO J 26: 2527-2539, 2007.

138. Levine B, Sinha S and Kroemer G: Bcl-2 family members: dual regulators of apoptosis and autophagy. Autophagy 4: 600-606, 2008.

139. Boyd JM, Gallo GJ, Elangovan B, et al: Bik, a novel deathinducing protein shares a distinct sequence motif with Bcl-2 family proteins and interacts with viral and cellular survivalpromoting proteins. Oncogene 11: 1921-1928, 1995.
140. Naumann U, Bähr O, Wolburg H, et al: Adenoviral expression of XIAP antisense RNA induces apoptosis in glioma cells and suppresses the growth of xenografts in nude mice. Gene Ther 14 147-161, 2007.

141. Oppermann M, Geilen CC, Fecker LF, Gillissen B, Daniel PT and Eberle J: Caspase-independent induction of apoptosis in human melanoma cells by the proapoptotic Bcl-2-related protein Nbk/Bik. Oncogene 24: 7369-7380, 2005.

142. Garcia N, Salamanca F, Astudillo-de la Vega H, et al: A molecular analysis by gene expression profiling reveals $B i k / N B K$ overexpression in sporadic breast tumor samples of Mexican females. BMC Cancer 5: 93, 2005

143. Hirsch DS, Shen Y, Dokmanovic M and Wu WJ: pp60 ${ }^{\text {c-Src }}$ phosphorylates and activates vacuolar protein sorting 34 to mediate cellular transformation. Cancer Res 70: 5974-5983, 2010.

144. Gao $\mathrm{P}$, Bauvy $\mathrm{C}$, Souquère $\mathrm{S}$, et al: The Bcl-2 homology domain 3 mimetic gossypol induces both Beclin 1-dependent and Beclin 1-independent cytoprotective autophagy in cancer cells. J Biol Chem 285: 25570-25581, 2010

145. Furuya N, Yu J, Byfield M, Pattingre S and Levine B: The evolutionarily conserved domain of Beclin 1 is required for Vps34 binding, autophagy and tumor suppressor function. Autophagy 1: 46-52, 2005

146. Musgrove EA and Sutherland RL: Biological determinants of endocrine resistance in breast cancer. Nat Rev Cancer 9 : 631-643, 2009

147. Dancey J: mTOR signaling and drug development in cancer. Nat Rev Clin Oncol 7: 209-219, 2010.

148. Ciafrè SA, Galardi S, Mangiola A, et al: Extensive modulation of a set of microRNAs in primary glioblastoma. Biochem Biophys Res Commun 334: 1351-1358, 2005.

149. Pallante P, Visone R, Ferracin M, et al: MicroRNA deregulation in human thyroid papillary carcinomas. Endocr Relat Cancer 13 497-508, 2006

150. Kondo N, Toyama T, Sugiura H, Fujii Y and Yamashita H miR-206 expression is down-regulated in estrogen receptor $\alpha$-positive human breast cancer. Cancer Res 68: 5004-5008, 2008

151. Rao X, Di Leva G, Li M, et al: MicroRNA-221/222 confers breast cancer fulvestrant resistance by regulating multiple signaling pathways. Oncogene 30: 1082-1097, 2011.

152. Sachdeva M, Wu H, Ru P, Hwang L, Trieu V and Mo YY: MicroRNA-101-mediated Akt activation and estrogen-independent growth. Oncogene 30: 822-831, 2011.

153. Miller TE, Ghoshal K, Ramaswamy B, et al: MicroRNA-221/222 confers tamoxifen resistance in breast cancer by targeting p27 ${ }^{\mathrm{Kipl}}$. J Biol Chem 283: 29897-29903, 2008.

154. Kovalchuk O, Filkowski J, Meservy J, et al: Involvement of microRNA-451 in resistance of the MCF-7 breast cancer cells to chemotherapeutic drug doxorubicin. Mol Cancer Ther 7: 2152-2159, 2008.

155. Liang Z, Wu H, Xia J, et al: Involvement of miR-326 in chemotherapy resistance of breast cancer through modulating expression of multidrug resistance-associated protein 1 . Biochem Pharmacol 79: 817-824, 2010.

156. Xin F, Li M, Balch C, et al: Computational analysis of microRNA profiles and their target genes suggests significant involvement in breast cancer antiestrogen resistance. Bioinformatics 25: 430-434, 2009.

157. Guardavaccaro D and Clevers $\mathrm{H}$ : Wnt/ $\beta$-catenin and MAPK signaling: allies and enemies in different battlefields. Sci Signal 5: pe15, 2012.

158. Gabrovska PN, Smith RA, Tiang T, Weinstein SR, Haupt LM and Griffiths LR: Development of an eight gene expression profile implicating human breast tumours of all grade. Mol Biol Rep 39: 3879-3892, 2012

159. Khramtsov AI, Khramtsova GF, Tretiakova M, Huo D, Olopade OI and Goss KH: Wnt/ $\beta$-catenin pathway activation is enriched in basal-like breast cancers and predicts poor outcome. Am J Pathol 176: 2911-2920, 2010.

160. Loh YN, Hedditch EL, Baker LA, Jary E, Ward RL and Ford CE The Wnt signalling pathway is upregulated in an in vitro model of acquired tamoxifen resistant breast cancer. BMC Cancer 13 174, 2013.

161. Katoh M: Comparative genomics on Wnt3-Wnt9b gene cluster. Int J Mol Med 15: 743-747, 2005.

162. Rubin JS, Bottaro DP, Chedid M, et al: Keratinocyte growth factor. Cell Biol Int 19: 399-411, 1995.

163. Rubin JS, Bottaro DP, Chedid M, et al: Keratinocyte growth factor as a cytokine that mediates mesenchymal-epithelial interaction. EXS 74: 191-214, 1995. 
164. Kumar V, Green S, Staub A and Chambon P: Localisation of the oestradiol-binding and putative DNA-binding domains of the human oestrogen receptor. EMBO J 5: 2231-2236, 1986.

165. Berry M, Metzger D and Chambon P: Role of the two activating domains of the oestrogen receptor in the cell-type and promotercontext dependent agonistic activity of the anti-oestrogen 4-hydroxytamoxifen. EMBO J 9: 2811-2818, 1990.

166. Mader S, Chambon P and White JH: Defining a minimal estrogen receptor DNA binding domain. Nucleic Acids Res 21 : 1125-1132, 1993.

167. Wang Z, Li Y, Banerjee S and Sarkar FH: Emerging role of Notch in stem cells and cancer. Cancer Lett 279: 8-12, 2009.

168. Shi TP, Xu H, Wei JF, et al: Association of low expression of notch-1 and jagged-1 in human papillary bladder cancer and shorter survival. J Urol 180: 361-366, 2008.

169. Al Saleh S, Sharaf LH and Luqmani YA: Signalling pathways involved in endocrine resistance in breast cancer and associations with epithelial to mesenchymal transition (Review). Int J Oncol 38: 1197-1217, 2011

170. Dontu G, Jackson KW, McNicholas E, Kawamura MJ, Abdallah WM and Wicha MS: Role of Notch signaling in cell-fate determination of human mammary stem/progenitor cells. Breast Cancer Res 6: R605-R615, 2004.

171. Stylianou S, Clarke RB and Brennan K: Aberrant activation of notch signaling in human breast cancer. Cancer Res 66 1517-1525, 2006.

172. Rizzo P, Miao H, D'Souza G, et al: Cross-talk between notch and the estrogen receptor in breast cancer suggests novel therapeutic approaches. Cancer Res 68: 5226-5235, 2008.

173. Wang Z, Li Y, Ahmad A, et al: Targeting Notch signaling pathway to overcome drug resistance for cancer therapy. Biochim Biophys Acta 1806: 258-267, 2010.

174. Hurvitz SA and Pietras RJ: Rational management of endocrine resistance in breast cancer: a comprehensive review of estrogen receptor biology, treatment options, and future directions. Cancer 113: 2385-2397, 2008.

175. Dibb NJ, Dilworth SM and Mol CD: Switching on kinases: oncogenic activation of BRAF and the PDGFR family. Nat Rev Cancer 4: 718-727, 2004.
176. Weigel MT, Ghazoui Z, Dunbier A, Pancholi S, Dowsett M and Martin LA: Preclinical and clinical studies of estrogen deprivation support the PDGF/Abl pathway as a novel therapeutic target for overcoming endocrine resistance in breast cancer. Breast Cancer Res 14: R78, 2012.

177. Pancholi V: Multifunctional $\alpha$-enolase: its role in diseases. Cell Mol Life Sci 58: 902-920, 2001.

178. Jiang BH, Agani F, Passaniti A and Semenza GL: V-SRC induces expression of hypoxia-inducible factor 1 (HIF-1) and transcription of genes encoding vascular endothelial growth factor and enolase 1: involvement of HIF-1 in tumor progression. Cancer Res 57: 5328-5335, 1997.

179. Wygrecka M, Marsh LM, Morty RE, et al: Enolase-1 promotes plasminogen-mediated recruitment of monocytes to the acutely inflamed lung. Blood 113: 5588-5598, 2009.

180. Dudani AK, Cummings C, Hashemi S and Ganz PR: Isolation of a novel $45 \mathrm{kDa}$ plasminogen receptor from human endothelial cells. Thromb Res 69: 185-196, 1993.

181. Peebles KA, Duncan MW, Ruch RJ and Malkinson AM Proteomic analysis of a neoplastic mouse lung epithelial cell line whose tumorigenicity has been abrogated by transfection with the gap junction structural gene for connexin 43, Gjal. Carcinogenesis 24: 651-657, 2003 .

182. Wu W, Tang X, Hu W, Lotan R, Hong WK and Mao L: Identification and validation of metastasis-associated proteins in head and neck cancer cell lines by two-dimensional electrophoresis and mass spectrometry. Clin Exp Metastasis 19: 319-326, 2002.

183. Ray R and Miller DM: Cloning and characterization of a human c-myc promoter-binding protein. Mol Cell Biol 11: 2154-2161, 1991.

184. Tu SH, Chang CC, Chen CS, et al: Increased expression of enolase $\alpha$ in human breast cancer confers tamoxifen resistance in human breast cancer cells. Breast Cancer Res Treat 121: $539-553,2010$ 